\title{
A system of indicators and criteria for evaluation of the level of functional stability of information heterogenic networks
}

\author{
Maksymuk O.V.. , Sobchuk V.V. ${ }^{2}$, Salanda I. P. ${ }^{3}$, Sachuk Yu. V. ${ }^{2}$ \\ ${ }^{1}$ Ivan Franko National University of Lviv, \\ 1 Universytetska Str., 79000, Lviv, Ukraine \\ ${ }^{2}$ Lesya Ukrainka Eastern European National University, \\ 13 Prosp. Voli, 43025, Lutsk, Ukraine \\ ${ }^{3}$ Taras Shevchenko Regional Humanitarian and Pedagogical Academy of Kremenets, \\ 1 Prov. Litseynyy, 47003, Kremenets', Ukraine
}

(Received 1 November 2019; Revised 14 July 2020; Accepted 15 July 2020)

\begin{abstract}
The mechanisms of self-organization of information heterogeneous networks have been analyzed in this article and new indicators and criteria for defining functionally stable networks have been suggested in accordance with the concept of SON, as well as a mathematical model of relevant network processes based on hypergraphs providing the required parameters and performance indicators of the mentioned hypernet has been rigorously substantiated. Due to the suggested indicators and criteria, we can evaluate and compare different structures of the high-connectivity networks, and apply them to the creation of a methodology for optimal use of the system redundancy when parrying the effects of accidental situations. It is expedient to use these indicators for up-to-date and advanced networks that are wireless, dynamic, self-organizing since, under the restructuring, they allow taking into account a certain number of elements, the destruction of which does not affect the functional stability of the network.
\end{abstract}

Keywords: functional stability, information heterogeneous network, self-organization, hypernet.

2010 MSC: $68 \mathrm{U} 35$

DOI: $10.23939 / \mathrm{mmc} 2020.02 .285$

\section{Introduction}

The processes of formation and providing the existence of the information society are grounded for all countries on the common technological basis, which is the information and communication infrastructure, and the development of the society is accompanied by the development and implementation of the latest technologies with the provision of automation of most functions. However, such systems have difficulties due to the increasing number of objects and due to the integration of heterogeneous systems into one heterogeneous information network based on its self-organization.

Nowadays, we can solve data transmission problems by improving the efficiency of the spectrum of networks and by implementing a new 5G-based technology of network architecture. WLAN technologies such as Wi-Fi play a key role in offload access to the Internet. The new information networks will use the technology at the level of radio reception: LTE-M, NB-loT, 5G New Radio with MIMO, Wi-Fi, Sigfox, 802.11p and Lora, and other newest technologies. These technologies have different parameters and are intended to operate at different levels [1-3].

Therefore, at the present stage of development of telecommunications, the issues of building heterogeneous information networks are urgent, and the development of a scientific and methodological apparatus for ensuring the properties of self-organization, reconfiguration, etc. is also important. 


\section{The problem formulation}

Investigation of the existing scientifically grounded approaches to improving the efficiency of complex technical systems, which include the area of information heterogeneous networks, has led to the conclusion that for the last years a new priority approach has formed which is concerned with providing the system with properties of functional stability.

The peculiarity of the process of heterogeneous network modeling is to take into account the interaction and the possible confrontation of different technologies in the process of functioning of the heterogeneous communication network as well as adaptation and transformation, if necessary, of its structure. Demand for traffic, development of new services, and expansion of the range of services require of networks the abilities to adjust and rearrange their structure.

The solution to the problem of constructing heterogeneous information networks implies the development of the concept of an information heterogeneous network which would be endowed with self-organization features, the improvement of the mathematical model, and the determination of the indicators and criteria of functional stability for formalizing the process of providing self-organization, as well as evaluating the level of stability. For the purpose of evaluating the level of functional stability, the indicators, criteria, estimates, and the methods for their determining or calculating are to be developed.

\section{The analysis of publications}

The trends in the development of information networks reflect the need for sharing of segments of the network or the entire network by several operators to extend the range of services and their quality [4]. Today, there are mechanisms for sharing the transport network and there is a need to connect segments of the entire network. The information network infrastructure involves the use of nodes that can be transferred into the cloud, and most network functions to be virtualized [5].

In this regard, it is necessary to integrate heterogeneous networks into one heterogeneous system with a common management system that uses a cognitive approach and is endowed with functions of self-organization under the conditions of the influence of destabilizing factors. The network structure should support thousands of new directions, and, the most important, it should be aimed at maintaining not only the consumer subscriber sector, but also at the maintenance of such fields as manufacturing at plants, power engineering, health care, and transport, municipal realm and others [6]. Therefore, such a network must be highly resistant to all types of destructive effects and their impact factors.

Mathematical formalization of functional stability of information heterogeneous networks is the first scientifically grounded step of the creation of methodological bases of providing functional stability. The analysis of the theory of functional stability concerning the methods of modeling complex technical systems has shown that there are relevant scientific works for dynamic systems based on the use of graph theory. However, when considering a network from the point of view of structural stability, the failure of a switching node or of a communication line entails the destruction of the communication channels of the secondary networks, which on the graphs of these networks are non-adjacent $[7,8]$. Thus, there is a need to introduce new concepts in the theory of information networks, namely the concept of "hypernet". Since the methods of the known theories do not always allow studying hypernets, there is a need to develop an appropriate methodological apparatus and to create new concepts and definitions.

Recent publications and studies on the construction of heterogeneous networks have focused on ensuring the self-organization feature of the networks. At the same time, the issue of network functioning under conditions of destabilizing factors has received insufficient attention. The issues of evaluating the level of functional stability were covered in a qualitative form. The indicators having been suggested by the researchers cannot be applied to heterogeneous networks. Therefore, the issue of developing 
indicators and criteria for evaluating the level of functional stability is an important scientific task for ensuring the functioning of a heterogeneous network.

Therefore, the problem of determining the indicators and criteria for the functional stability of information heterogeneous networks requires substantiation of the proper dependencies and approaches and it remains relevant.

The objective of the article is to develop a system of indicators and criteria for formalizing the processes for ensuring the functional stability (including self-organization) of information heterogeneous networks.

\section{Hypernet}

One of the main features of self-organizing systems is the ability to resist the tendencies of random changes of the network parameters, the ability to adapt to the changing conditions, if necessary by transforming its structure.

A mathematical model of the information heterogeneous network that gives an opportunity to describe the network processes, namely the processes of restructuring and self-adjusting in the conditions of connecting new nodes and their removal is a hypernet.

For the first time, the concept of "hypernet" as a mathematical object has been mentioned in Popkov's paper [9]. The introduced concept is epistemologically different from the concepts known in the literature. The basic difference between a hypernet and other structural models is that more than two forming sets being involved in the creation of its structure.

Since the methods of the known theories do not always allow us to investigate hypernets, it is necessary to develop an appropriate methodological apparatus and to create new concepts and definitions.

\section{Hypernetic models}

Formally, an abstract hypernet can be described by the six $A S=(X, V, R ; P, F, W)$, which includes the following objects:

$X=\left(x_{1}, x_{2}, \ldots, x_{n}\right)$ is the set of vertices;

$V=\left(\nu_{1}, \nu_{2}, \ldots, \nu_{g}\right)$ is the set of branches;

$R=\left(r_{1}, r_{2}, \ldots, r_{m}\right)$ is the set of edges;

$P: V \rightarrow 2^{X}$ is a mapping that assigns to each element $\nu \in V$ the set $P(\nu)$ of $X$ its vertices. Thus, the mapping defines a hypergraph $P S=(X, V ; P)$;

$F: R \rightarrow 2_{P S}^{V}$ is a mapping that assigns to each element $r \in R$ the set of $F(r)$ of its branches, and the family of subsets of branches $2_{P S}^{V}$ contains such subsets whose branches form a connected part of the hypergraph $P S$; the mapping $F$ determines the hypergraph $F S=(V, R ; F)$;

$W: r \rightarrow 2^{P(F(r))} \forall r \in R$ is a mapping that assigns to each element $r \in R$ the subset of $W(r)$ of $P(F(r))$ its vertices, where $P(F(r))$ is a set of vertices in $P S$, incident to the branches $F(r)$ of $V$. Thus, the mapping $W$ determines the hypergraph $W S=(X, R ; W)$.

In other words, the vertex $x \in X$ is incident to the branch $\nu \in V$ if and only if $x \in P(v)$; the branch $\nu \in V$ is incident to the edge $r \in R$ if and only if $v \in F(r)$; the edge $r \in R$ is incident to the vertex $x \in X$ if and only if $x \in W(r)$. Two elements from different sets are weakly incident if there is an element from the third set which is incident to both them. It is obvious that weakly incident elements can also be incident; the inverse statement is incorrect.

For the investigation of functional stability, it is important to describe the concept of "the removal" of network elements. There are three ways to remove vertices from a hypernet:

1. The vertex is removed internally if all its incident edges are removed, i.e., in the $W S$ graph, the vertex will be isolated. 
2. The vertex is removed externally if all weakly incident (but not incident) edges are removed. In the $W S$ graph, this corresponds to the removal of some subset of edges, and in the $F S$ hypergraph, this corresponds to the weak removal of the subset of edges.

3. The vertex is removed if this vertex and all branches incident to it are removed.

The concept of a route plays a fundamental role in the analysis of the connectivity of hypernets and their metric properties. The fact that the routes in the hypernets are given differently contributes to the expansion of the means of hypernet theory.

In the hypernet $S=(X, V, R)$, a finite sequence $\mu=\left(x_{1}, r_{1}, x_{2}, \ldots, x_{k-1}, r_{k-1}, x_{k}\right)$, composed of the elements $X, R$ such that the vertices and the edges alternate, and any two adjacent elements are incident is called a route.

In the hypernet $S=(X, V, R)$, a finite sequence $\mu$, in which a pair of adjacent elements $\left(x_{i}, r_{i}\right)$ are incident, and $\left(r_{i}, x_{i+1}\right)$ are weakly incident is called a quasi-route.

If in the definition of the route, incident is replaced with weak incident, we obtain a definition of $a$ weak route.

The rank $\delta_{\mu}$ of the route $\mu$ (quasi-route, weak route) is the number of edges (or parts of edges), which belong to that route.

The distance (quasi-distance, weak distance) between the vertices is numerically equal to the rank of the shortest route (quasi-route, weak route) connecting these vertices, it is denoted by $\delta(x, y), \bar{\delta}(x, y)$, $\overline{\bar{\delta}}(x, y)$, respectively

The length of an edge (or of its part) is the number of branches incident to that edge (part of the edge).

The length $\rho_{\mu}$ of the route $\mu$ (quasi-route, weak route) is equal to the total length of the edges (parts of edges) that are included in the route $\mu$.

The distance (quasi-distance, weak distance) between the vertices $x, y \in X$ in the hypernet $S$ is equal to the length of the shortest route (quasi-route, weak route) connecting these vertices.

We define the diameter (quasi-diameter, weak diameter) of the hypernet $S$ as the value of maximal distance (quasi-distance, weak distance) of the vertices of the hypernet.

\section{Functionally stable hypernets according to the $(k, d)$-stability criterion}

From the aforesaid theory, it follows that for a hypernet it is necessary to define several types of properties of $(k, d)$-stability. Different models can require different types of vertex removal, and a need to find out how a type of removal affects a diameter can emerge. Therefore, according to the type of removal of the switching node and to the method of specifying the route, nine types of properties can be defined (Table 1$)$.

Table 1.

\begin{tabular}{|c|l|l|l|}
\hline Type of removal & \multicolumn{1}{|c|}{ Diameter } & \multicolumn{1}{|c|}{ Quasi-diameter } & \multicolumn{1}{c|}{ Weak diameter } \\
\hline Removal & $\begin{array}{l}(k, d) \text {-stability in terms } \\
\text { of diameter and removal }\end{array}$ & $\begin{array}{l}(k, d) \text {-stability in terms of } \\
\text { quasi-diameter and removal }\end{array}$ & $\begin{array}{l}(k, d) \text {-stability in terms of } \\
\text { weak diameter and removal }\end{array}$ \\
\hline Internal removal & $\begin{array}{l}(k, d) \text {-stability in terms } \\
\text { of diameter and internal } \\
\text { removal }\end{array}$ & $\begin{array}{l}(k, d) \text {-stability in terms of } \\
\text { quasi-diameter and internal } \\
\text { removal }\end{array}$ & $\begin{array}{l}(k, d) \text {-stability in terms of } \\
\text { weak diameter and internal } \\
\text { removal }\end{array}$ \\
\hline External removal & $\begin{array}{l}(k, d) \text {-stability in terms } \\
\text { of diameter and external } \\
\text { removal }\end{array}$ & $\begin{array}{l}(k, d) \text {-stability in terms of } \\
\text { quasi-diameter and external } \\
\text { removal }\end{array}$ & $\begin{array}{l}\text { (k,d)-stability in terms of } \\
\text { weak diameter and external } \\
\text { removal }\end{array}$ \\
\hline
\end{tabular}

In Fig. 1, an example of an unstable hypernet when removing vertices externally is shown.

In this regard, it is expedient to introduce a new indicator of functional stability, namely $(k, d)$ stability of hypernets, where $k$ is the number of elements of optimal destruction. For the first time, the concept of $(k, d)$-stability is found in [9]. 

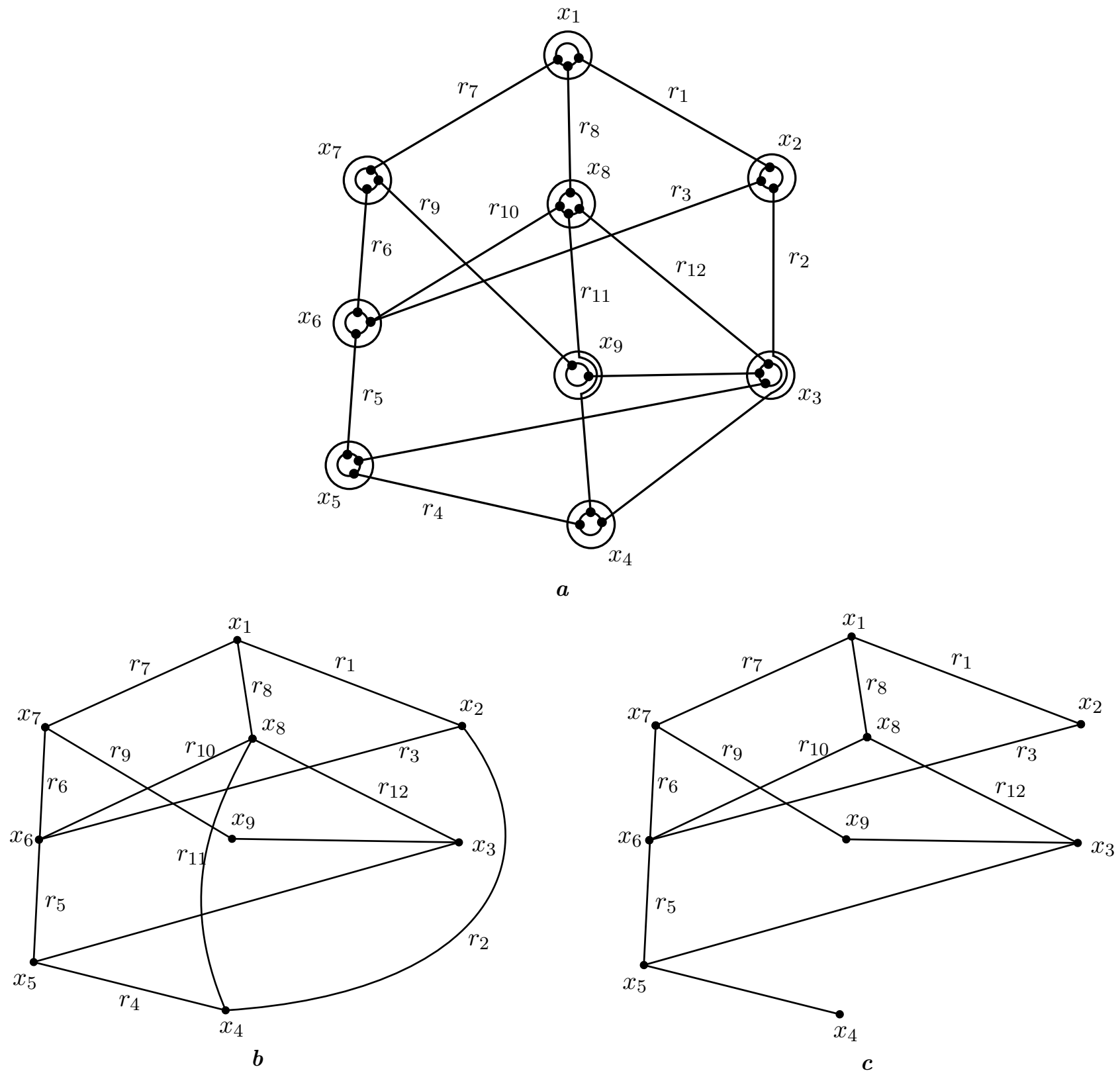

Fig. 1. Hypernet not retaining $(2,3)$-stability in terms of diameter and external removal: hypernet, $(\boldsymbol{a})$; the primary network of the hypernet, $(\boldsymbol{b})$; the primary network of the hypernet after external removal of vertices $x_{3}$ and $x_{9},(\boldsymbol{c})$.

A hypernet $S$ is called $(k, d)$-stable in terms of diameter and internal (external) removal, if under the internal (external) removal of any of its $k$ vertices $\left\{x_{i}\right\}$, the diameter of the sub-hypernet $S^{\prime}=$ $\left(X /\left\{x_{i}\right\}, V^{\prime}, R^{\prime}\right)$ does not exceed $d$.

A hypernet $S$ is called $(k, d)$-stable in terms of quasi-diameter and internal (external) removal, if under the internal (external) removal of any of its $k$ vertices $\left\{x_{i}\right\}$, the quasi-diameter of the subhypernet $S^{\prime}=\left(X /\left\{x_{i}\right\}, V^{\prime}, R^{\prime}\right)$ does not exceed $d$ (see Fig. 2).

A hypernet $S$ is called $(k, d)$-stable in terms of weak diameter and internal (external) removal, if under the internal (external) removal of any $k$ of its vertices $\left\{x_{i}\right\}$ the weak diameter of the sub-hypernet $S^{\prime}=\left(X /\left\{x_{i}\right\}, V^{\prime}, R^{\prime}\right)$ does not exceed $d$. 

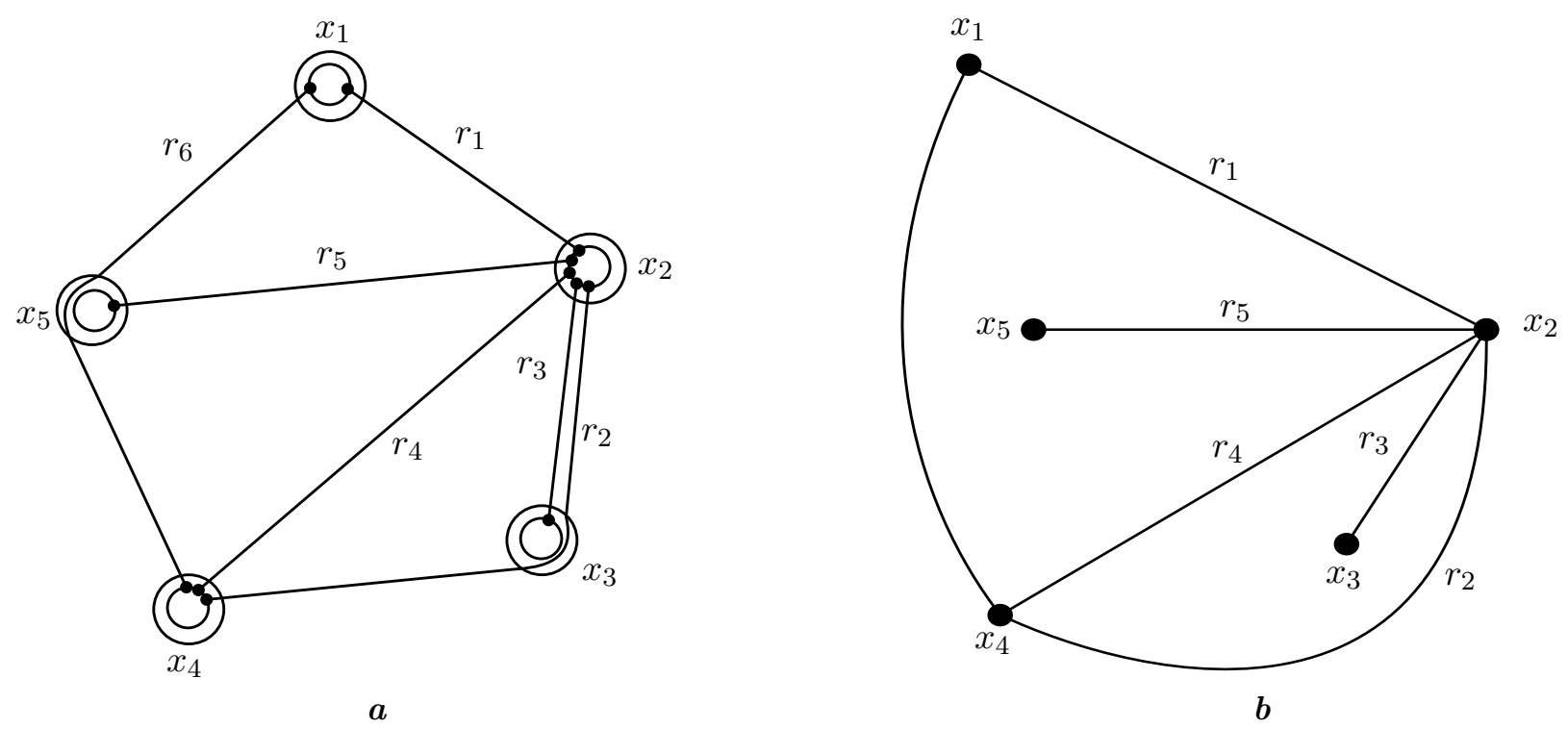

Fig. 2. Hypernet retaining (2,2)-stability in terms of diameter and external removal.

That is, we will be interested in the networks that, after removing $k$ switching nodes, retain the specified connectivity and diameter. In the paper [9], the notion of $(k, d)$-edges stability for graphs is introduced. By analogy, we define this parameter for hyperlinks.

A hypernet $S$ is called $\left(k, d_{1}, l, d_{2}\right)$-stable in terms of diameter and internal (external) removal, if under the internal (external) removal of any of its $k$ vertices $\left\{x_{i}\right\}$ the diameter of the sub-hypernet $S^{\prime}=\left(X /\left\{x_{i}\right\}, V^{\prime}, R^{\prime}\right)$ does not exceed $d_{1}$, and under the removal of $l$ of its branches $\left\{v_{i}\right\}$ the diameter of the sub-hypernet $S^{\prime}=\left(X, V /\left\{v_{i}\right\}, R^{\prime}\right)$ does not exceed $d_{2}$.

A hypernet $S$ is called $\left(k, d_{1}, l, d_{2}\right)$-stable in terms of quasi-diameter and internal (external) removal, if under the internal (external) removal of any of its $k$ vertices $\left\{x_{i}\right\}$ the quasi-diameter of the subhypernet $S^{\prime}=\left(X /\left\{x_{i}\right\}, V^{\prime}, R^{\prime}\right)$ does not exceed $d_{1}$, and under the removal of $l$ of its branches $\left\{v_{i}\right\}$ the quasi-diameter of the sub-hypernet $S^{\prime}=\left(X, V /\left\{v_{i}\right\}, R^{\prime}\right)$ does not exceed $d_{2}$.

A hypernet $S$ is called $\left(k, d_{1}, l, d_{2}\right)$-stable in terms of weak diameter and internal (external) removal, if under the internal (external) removal of any of its $k$ vertices $\left\{x_{i}\right\}$ the weak diameter of the subhypernet $S^{\prime}=\left(X /\left\{x_{i}\right\}, V^{\prime}, R^{\prime}\right)$ does not exceed $d_{1}$, and under the removal of $l$ of its branches $\left\{v_{i}\right\}$ the weak diameter of the sub-hypernet $S^{\prime}=\left(X, V /\left\{v_{i}\right\}, R^{\prime}\right)$ does not exceed $d_{2}$.

In other words, we will consider the networks that remain connected after removing the $k$ transmission links or $l$ switching lines, and the resulting hypernets retain their proper diameters. Thus, adding to the model $(k, d)$-stability, we obtain the most complete model.

Indicators of functional $(k, d)$-stability of the structure.

1. The number of $(k, d)$-stability is the maximal number of vertices whose deletion together with the incident edges retains the diameter $d$ of the network.

2. The number of $\left(k, d_{1}, l, d_{2}\right)$-edges stability is the optimal number of vertices $k$ and edges $l$ after the removal of which the corresponding diameter is retained.

\section{Analysis of the stability of hypernets}

In [9], theorems and algorithms allowing to detect $(k, d)$-stability and edge-stability of graphs are considered. During the investigation, the adaptation of these algorithms for hypernets and hierarchical hypernets was performed. However, when solving real problems, the developed method can be applied only to the low-sized hyper networks, since finding all the links between two vertices is a time-consuming task. 
The following corollaries can be used to determine the $(k, d)$-stability of large-sized and mediumsized hypernets.

1. It is sufficient for the $(k, d)$-stability of $S$ under the removal that in the graph $G$ between any pair of vertices there exist $k$ independent links of the length not more than $d$.

2. It is sufficient for the $(k, d)$-stability of $S$ under the internal removal that in the graph $G$ between any pair of vertices there exist $k$ internally independent links of the length not more than $d$.

3. It is sufficient for the $(k, d)$-stability of $S$ under the external removal that in the graph $G$ between any pair of vertices there exist $k$ externally independent links of the length not more than $d$. Converse propositions are incorrect.

\section{Conclusions}

Due to the need to integrate heterogeneous networks into one heterogeneous system with a common management system, which uses a cognitive approach and is endowed with functions of self-organization under the influence of destabilizing factors, a mathematical model of the structure of a heterogeneous information network based on hypernet theory has been developed in this paper. An abstract hypernet as a mathematical model of information networks is universal since with this model it is possible to describe the structures that consist of different types of communication channels. By adding to the considered model the indicators and criteria of $(k, d)$-stability, we obtain the most complete model. By means of the suggested indicators and criteria, we can evaluate and compare different structures of the high-connectivity networks, and apply them to the creation of a methodology for optimal use of the system redundancy when parrying the effects of accidental situations.

[1] Honda H. On a model of target detection in molecular communication networks. Networks \& Heterogeneous Media. 14 (4), 633-657 (2019).

[2] Nicola W., Campbell S. A. Mean-field models for heterogeneous networks of two-dimensional integrate and fire neurons. Front. Comput. Neurosci. 7, Article 184, 1-25 (2013).

[3] Honda H. Local-in-time solvability of target detection model in molecular communication network. International Journal of Applied Mathematics. 31 (3), 427-455 (2018).

[4] Yaguache F. R., Ahola K. Containerized services orchestration for edge computing in software-defined wide area networks. International Journal of Computer Networks and Communications. 11 (5), 113-132 (2019).

[5] Kozelkov S., Bondarchuk A., Storchak K., Polovenya S., Miller Yu. Matematicheskaya model raspredeleniya informatsionnyih potokov. Problemy infokommunikatsiy. 1 (7), 13-22 (2018), (in Russian).

[6] Memos V. A. Efficient Multimedia Transmission over Scalable IoT Architecture. International Journal of Computer Network and Information Security. 10 (6), 27-39 (2018).

[7] Kulin M., Fortuna C., De Poorter E., Deschrijver D., Moerman I. Data-Driven Design of Intelligent Wireless Networks: An Overview and Tutorial. Sensors. 16 (6), 790-796 (2016).

[8] Salanda I. Barabash O., Musienko A. Systema pokaznykiv ta kryteriiv formalizatsii protsesiv zabezpechennia lokalnoi funktsionalnoi stiikosti rozghaluzhenykh informatsiinykh merezh. Naukove periodychne vydannia "Systemy upravlinnia, navihatsii ta zviazku". 1 (41), 122-126 (2017), (in Ukrainian).

[9] Popkov V.K. Matematicheskie modeli zhivuchesti setey svyazi. Novosibirsk, Computing Center of SD AS USSR (1990), (in Russian). 


\title{
Система показників і критеріїв для оцінки рівня функціональної стійкості інформаційних гетерогенних мереж
}

\author{
Максимук О. В. ${ }^{1}$, Собчук В. В. ${ }^{2}$, Саланда І. П. ${ }^{3}$, Сачук Ю. В. ${ }^{2}$ \\ 1 Львівсъкий начіональний університет імені Івана Франка, \\ вул. Університетсъка, 1, 79000, Львів, Україна \\ ${ }^{2}$ Східноєвропейсъкий начіональний університет імені Лесі Украӥнки, \\ просп. Волі, 13, 43025, Луцьк, Україна \\ ${ }^{3}$ Кременецька обласна гуманітарно-педагогічна академія ім. Тараса Шевченка, \\ пров. Лічейний, 1, 47003, Кременець, Україна
}

У статті проаналізовано механізми самоорганізації інформаційних гетерогенних мереж та запропоновано нові показники і критерії для визначення функціонально стійких мереж у відповідності до концепції SON, а також строго обгрунтовано математичну модель відповідних мережевих процесів на базі гіперграфів із забезпеченням потрібних параметрів і показників функціонування зазначеної мережі. За допомогою запропонованих показників та критеріїв можна оцінювати та порівнювати різні структури мереж з високим рівнем зв'язності, а також застосовувати їх для формування методики оптимального використання надмірності системи при парируванні наслідків позаштатних ситуацій. Дані показники доцільно використовувати для сучасних та перспективних мереж, які є безпровідними, динамічними, самоорганізуючими, оскільки вони дозволяють під час реструктуризації враховувати певну кількість елементів, пошкодження яких не впливає на функціональну стійкість мережі.

Ключові слова: функціональна стійкість, інформачійна гетерогенна мережа, самоорганізачія, гіпермережа. 